\title{
Stress-induced alterations of norepinephrine release in the bed nucleus of the stria terminalis of mice
}

Karl T. Schmidt ${ }^{1}$, Viren H. Makhijani ${ }^{1,2}$, Kristen M. Boyt ${ }^{1}$, Dipanwita Pati ${ }^{1}$, Melanie M. Pina ${ }^{1}$,

Isabel M. Bravo ${ }^{1}$, Jason L. Locke5 , Sara R. Jones5 ${ }^{5}$ Joyce Besheer ${ }^{1,2,3}$, and Zoé A. McElligott 2, 3, 4\#

1. Bowles Center for Alcohol Studies

2. Neuroscience Curriculum

3. Department of Psychiatry

4. Department of Pharmacology

University of North Carolina at Chapel Hill, Chapel Hill NC, USA, 27599

5. Department of Physiology and Pharmacology

Wake Forest School of Medicine, Winston-Salem, NC, USA, 27157

\# Corresponding author, zoemce@email.unc.edu 
Stress can drive adaptive changes to maintain survival during threatening stimuli. Chronic stress exposure, however, may result in pathological adaptations. A key neurotransmitter involved in stress signaling is norepinephrine. Previous studies show that stress elevates norepinephrine levels in the bed nucleus of the stria terminalis (BNST), a critical node regulating anxiety and upstream of stress responses. Here, we use mice expressing channelrhodopsin in norepinephrine neurons to selectively activate terminals in the BNST, and measure norepinephrine release with fast-scan cyclic voltammetry. Mice exposed to a single restraint session show an identical norepinephrine release profile compared to that of unexposed mice. Mice experiencing five days of restraint stress, however, show elevated noradrenergic release across multiple stimulation parameters, and reduced sensitivity to the $\alpha_{2}$-adrenergic receptor antagonist idazoxan. These data are the first to examine norepinephrine release in the BNST to tonic and phasic stimulation frequencies, and confirm that repeated stress alters autoreceptor sensitivity.

Stress; Norepinephrine; Fast-Scan Cyclic Voltammetry; Optogenetics; Bed Nucleus of the Stria Terminalis; Corticosterone

\section{DBH:Cre Mouse x Ai32 Mouse}
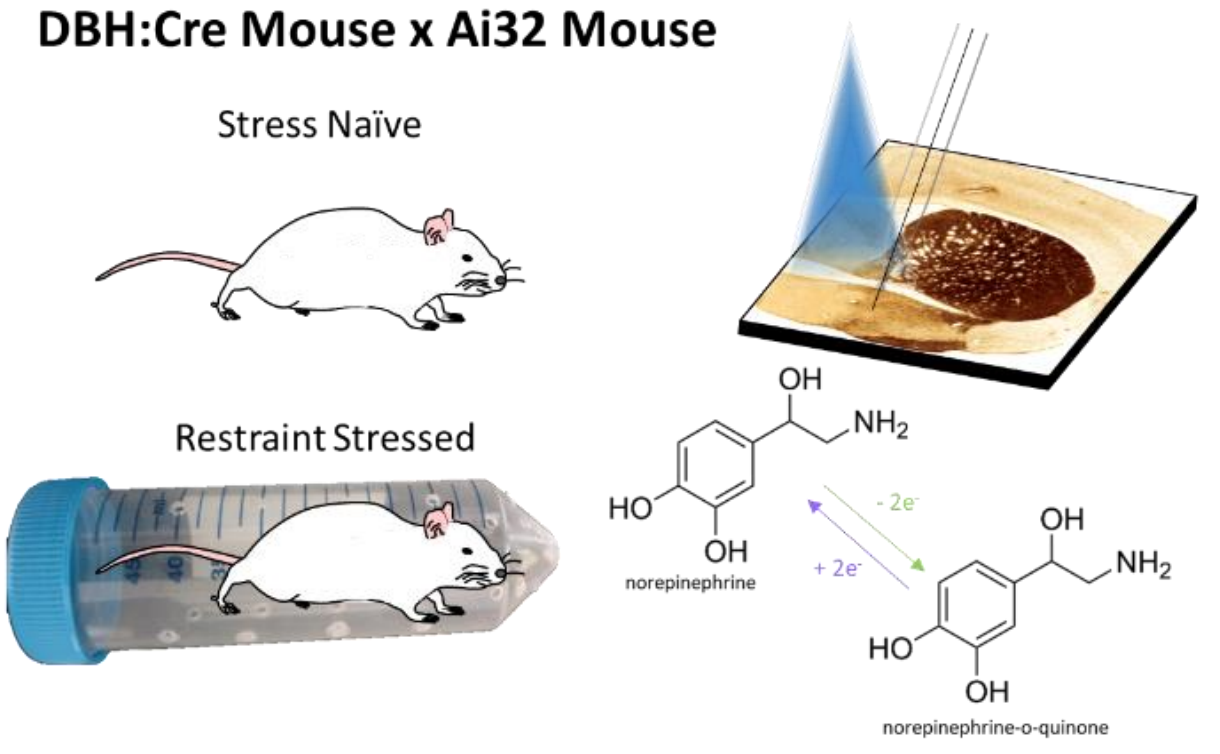
Stress is an important physiologic response to potentially harmful environmental stimuli. Under some conditions, however, such as chronic stress exposure or especially traumatic events, persistent alterations in the stress response occur, leading to abnormal and potentially maladaptive responses. Previous research has shown a central role of the catecholamine neurotransmitter norepinephrine (NE) in the physiological and behavioral stress responses ${ }^{1}$. NE release, in key downstream nuclei following stress has been implicated in a number of psychological disorders including addiction ${ }^{2-3}$, affective disorders ${ }^{1}$, and PTSD4.

Noradrenergic neurons project through two primary pathways in the brain: the dorsal noradrenergic bundle and ventral noradrenergic bundle. The pontine locus coeruleus (A6) gives rise to the dorsal noradrenergic bundle sending projections throughout the cortex, thalamus, hippocampus, cerebellum, and amygdala ${ }^{5-7}$. In contrast, the ventral noradrenergic bundle mainly arises from two nuclei, A1 of the rostral ventrolateral medulla and A2 of the nucleus of the solitary tract $^{6}$, and projects mainly to hypothalamus, parabrachial nucleus, midbrain, and bed nucleus of the stria terminalis (BNST)3, 6, 8. Of particular interest is the projection from the medullary noradrenergic nuclei (i.e. A1/A2) to the BNST because it comprises the densest region of NE terminals in the brain ${ }^{9-12}$ and serves as a critical nucleus for processing affective state ${ }^{13}$. Furthermore, multiple stressors have been shown to increase NE release in the BNST, and blockade of $\alpha_{1}$-adrenergic receptors ( $\alpha_{1}$-AR) in the BNST reduced circulating adrenocorticotropic hormone concentrations and anxiety-like behavior ${ }^{14}$. There appears to be a critical role of adrenergic receptors in the BNST in the response to stress, as chronic restraint stress prevents the ability of the region to express $\alpha_{1}$-AR dependent plasticity ${ }^{15}$ and multiple adrenergic receptors can drive release of corticotropin releasing factor within the BNST15-16.

Previously, we and others have demonstrated that stress exposure modulates norepinephrine release in the BNST in $\operatorname{rats}^{17-18}$. Due to innervation of multiple biogenic amine pathways, and a reliance on electrical stimulation, these studies could not be performed at physiologically relevant frequency patterns ${ }^{19-20}$, and it was challenging to isolate catecholamine 
release from noradrenergic terminals ${ }^{11}$. Here we use a combination of optogenetics and fast-scan cyclic voltammetry (FSCV) to examine stress-induced alterations in NE release in the BNST. Using a mouse line expressing Cre-recombinase driven by the dopamine-beta-hydroxylase (DBH::Cre) promoter crossed with the Allen Institute's "Ai32" mouse line ${ }^{21}$ that expresses channelrhodopsin (ChR2) in a Cre-recombinase dependent manner, we were able to selectively probe noradrenergic release in the BNST using optogenetically-driven stimulation with FSCV following various restraint stress exposure paradigms. We show that repeated restraint stress exposure, but not single stress exposure, enhances NE release in the BNST of mice. Our data suggests this phenomenon may be driven by alterations in $\alpha_{2}$-adrenergic receptor function.

\section{$\underline{\text { Results and Discussion }}$}

Before using the DBH:Cre(+/-)::Ai32(+/+) mice to examine stress-induced neuroadaptations, we first characterized the noradrenergic system in this line. Transgene expression did not alter tissue content of NE in the BNST, cortex, striatum, hippocampus, or amygdala as measured by high-performance liquid chromatography (data not shown). Using ex vivo patch-clamp electrophysiology, we recorded the activity of ChR2-eYFP ${ }^{+}$neurons of the A2 cell group in $300 \mu \mathrm{m}$ coronal slices of the nucleus of the solitary tract. These neurons showed light-evoked action potentials at both low-tonic frequencies (10 pulses, $1 \mathrm{~Hz}, 5 \mathrm{~ms}, 473 \mathrm{~nm}$; Fig. 1A) and high-phasic frequencies (15 Hz; Fig. 1B) with high fidelity ( $\mathrm{n}=5$ cells). Furthermore, we observed a dense fiber projection of noradrenergic neurons in the ventral BNST (Fig. 1C). Repeated optogenetic stimulations of equal parameters (20 pulses, $10 \mathrm{~Hz}, 5 \mathrm{~ms}, 473 \mathrm{~nm}$ ) with 5 min between each stimulation induced stable NE release with an average peak concentration of $0.1689 \mu \mathrm{M}$ NE at each stimulation (Fig. 1D). This concentration is in line with what was previously measured in vivo in rats with supraphysiological frequencies and higher pulse numbers of electrical stimulation at distal sites ${ }^{11,}{ }^{18,22}$. Previously reported dopamine release using a 
A

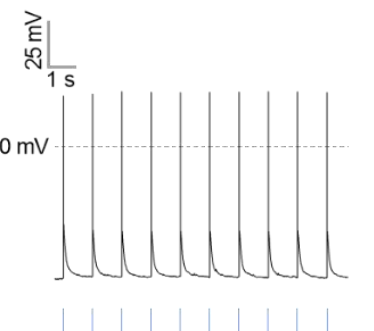

C

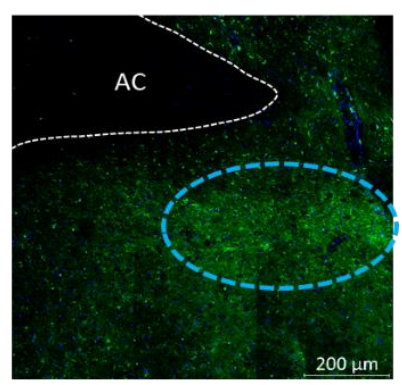

$\mathbf{E}$

G
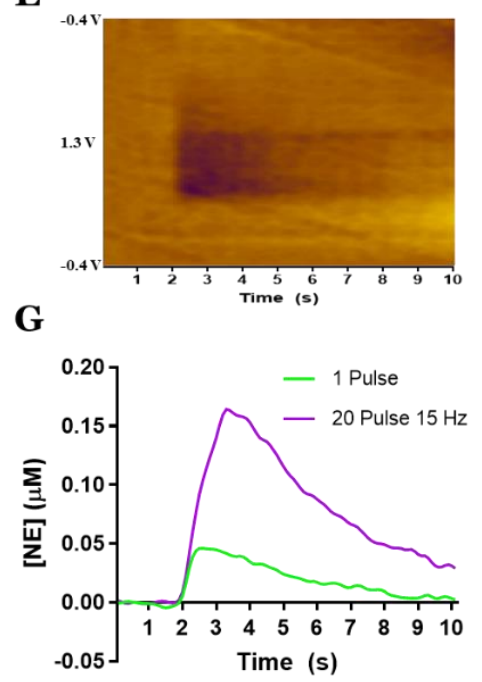

B
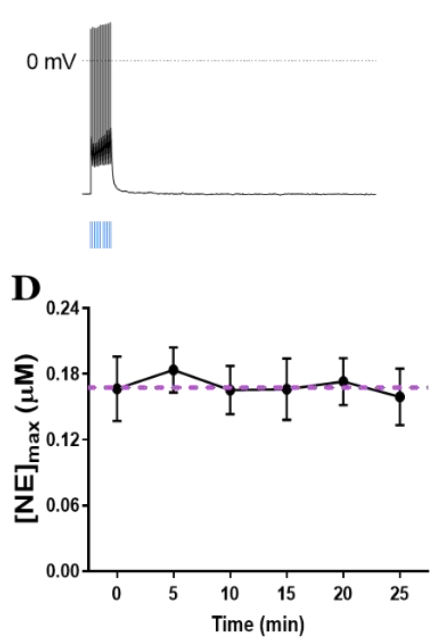

$\mathbf{F}$

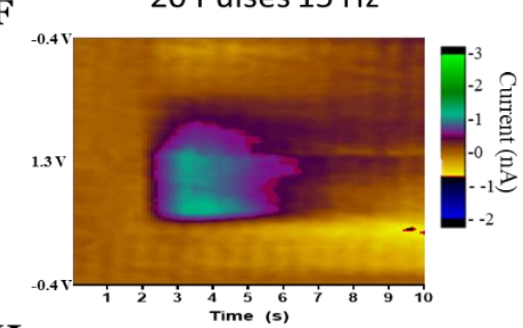

$\mathbf{H}$

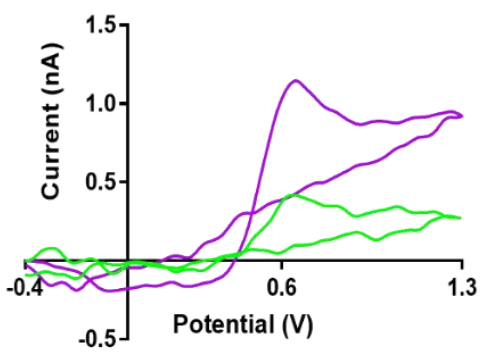

Figure 1. DBH:Cre(+/-)::Ai32(+/+) mice act as a reliable model to study noradrenergic function. Patch clamp electrophysiology shows that GFP+ neurons in A2 fire action potentials in response to optogenetic stimulation (blue bars) at both $1 \mathrm{~Hz}$ (A) and $15 \mathrm{~Hz}$ (B) frequencies. C) Terminal projections (green $=\mathrm{GFP}$ ) in fusiform subnucleus (outlined in cyan dashes) of the ventral bed nucleus of the stria terminalis. D) $10 \mathrm{~Hz}, 20$ pulse optogenetic stimulation of the vBNST induces consistent concentrations of norepinephrine release over multiple stimulations. Mean \pm SEM; $n=4$ recording sites from 4 mice; $p=0.297$. E) Color plot representing NE release following single pulse of optogenetic stimulation. F) Color plot representing $\mathrm{NE}$ release following 20 pulses at $15 \mathrm{~Hz}$ of optogenetic stimulation. G) Representative norepinephrine concentration over time following either single pulse (lime) or 20 pulses at $15 \mathrm{~Hz}$ (lilac). Optogenetic stimulation occurred at $2 \mathrm{~s}$. H) Representative cyclic voltammograms of either single pulse (lime) or 20 pulses at $15 \mathrm{~Hz}$ (lilac).

DAT::CRE line crossed with Ai32 mice indicated a decrease in optogenetically-evoked dopamine with repeated stimulations in the striatum ${ }^{23}$. As we do not see this consecutive decrease in our recordings, it may be a result of differences in Cre-driver line (as the DAT::Cre line has altered clearance mechanisms), brain region, or catecholamine. Furthermore, we observed stimulation dependent $\mathrm{NE}$ release with low concentrations $($ mean $[\mathrm{NE}]=$ o.037 $\mu \mathrm{M} ; \mathrm{n}=8$ ) detected following a single pulse of light and higher concentrations $($ mean $[\mathrm{NE}]=0.243 \mu \mathrm{M} ; \mathrm{n}=6)$ following phasic burst-like (20 pulses, $15 \mathrm{~Hz}$ ) stimulation (Fig. $1 \mathrm{E}, \mathrm{F}, \mathrm{G}, \mathrm{H})$.

After validating the utility of the DBH:Cre(+/)::Ai32(+/+) line to study the release and uptake of NE in the vBNST, we next examined if in vivo stress exposure would engage plasticity within this circuit. To ensure that our paradigm engaged 
norepinephrine neurons and elicited a stress response, we exposed mice on the same background to a 2 -h restraint stress paradigm. Immediately following a restraint stress session, we collected trunk blood and analyzed it for plasma corticosterone (CORT) concentrations. As anticipated, restraint stress exposure significantly elevated CORT (Fig. 2A). Simultaneously, we retrieved the brains from these mice and used dual fluorophore fluorescent in situ hybridization (FISH) to probe for $c F$ os and $D B H$ mRNA in the nucleus of solitary tract. Restraint stress increased cFos translation in the A2 NE neurons (Fig. 2B). These data suggest that our stress paradigm stimulates activity in $\mathrm{NE}$ neurons and engages the hypothalamicpituitary-adrenal stress axis.

We then performed slice optogenetics assisted FSCV to measure NE release in the BNST of mice from one of three conditions: stress naïve, single 2-hour restraint stress exposure, or repeated 5 days, 2-hour restraint stress exposure. All stress mice were recorded from on the day immediately following stress exposure to examine an adaptive response. Our stimulation

\section{$\mathbf{A}$}

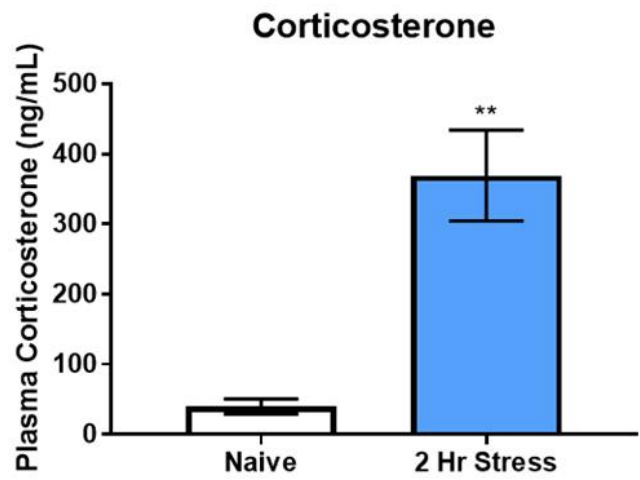

$\mathbf{B}$
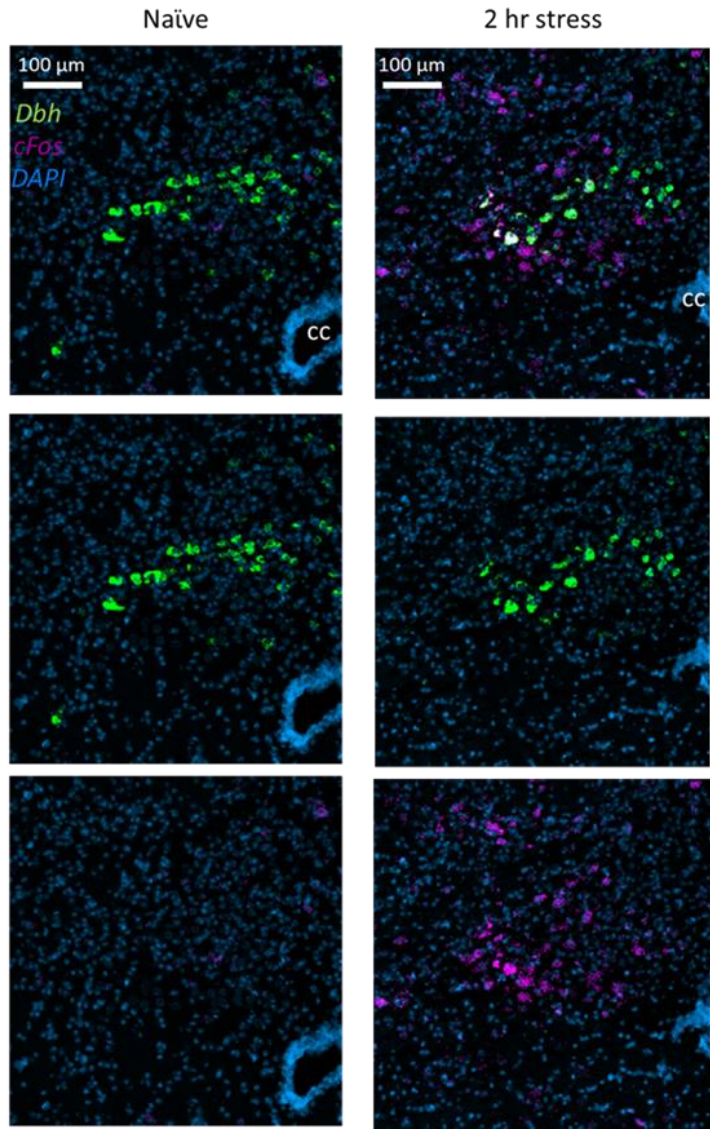

Figure 2. Two hours of restraint increases corticosterone and cFos expression. A) Plasma corticosterone $(\mathrm{ng} / \mathrm{mL})$ from naïve and $2 \mathrm{hr}$ stress mice. Mean \pm SEM; $\mathrm{n}=5$ mice/group. Unpaired t-test, $t=5.027 ; p=0.001$. B) Nucleus of the solitary tract double fluorescent in situ hybridization showing $\mathrm{DBH}, \mathrm{cFos}$, and DAPI in both stress naïve and restraint stressed mice. $\mathrm{CC}=$ central canal.

parameters examined various frequency (20 pulses at 1, 2, 5, 10, $15 \mathrm{~Hz}$ ) and pulse number (1, 2, 
$\mathbf{A}$

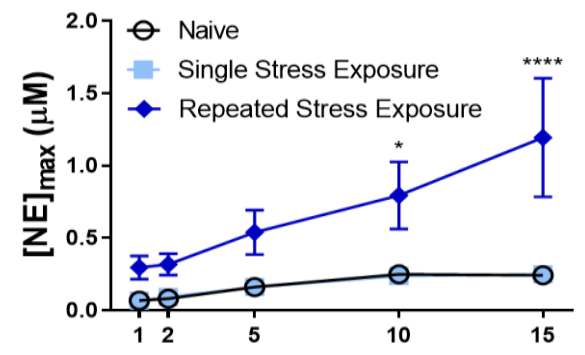

Frequency $(\mathrm{Hz})$ of Light Pulses (20 P, $5 \mathrm{~ms}, 473 \mathrm{~nm}$ )

B

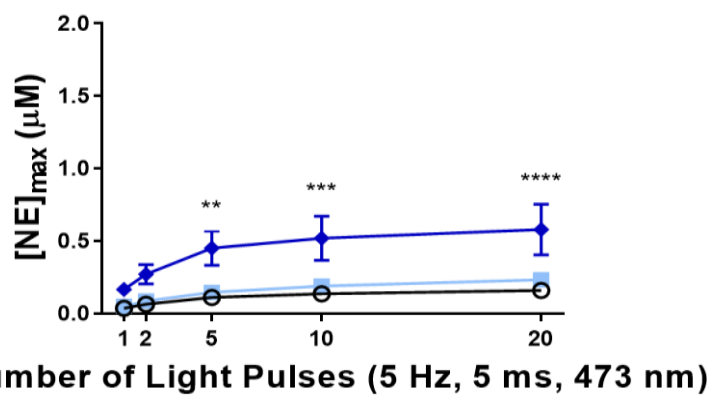

C

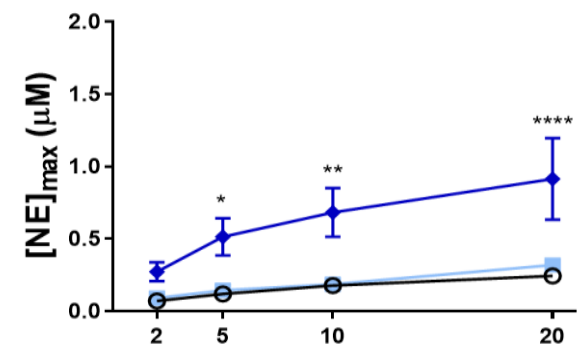

Number of Light Pulses (10 Hz, $5 \mathrm{~ms}, 473 \mathrm{~nm})$

Figure 3. Repeated stress exposure increases norepinephrine release at multiple stimulation parameters. A) Varied frequencies of 20 pulse stimulations induce different peak concentrations of norepinephrine ([NE]max) between stress naïve, single stress exposed, and repeated stress exposed mice. Two-way repeated measures ANOVA, main effects of frequency $(\mathrm{F}=7.66, \mathrm{p}<0.0001)$ and stress exposure $(\mathrm{F}=7.733, \mathrm{p}=0.004)$ with a significant interaction $(\mathrm{F}=2.484, \mathrm{p}=0.0199)$. B) Varied number of light pulses at $5 \mathrm{~Hz}$ stimulation induce different peak concentrations of norepinephrine between stress naïve, single stress exposed, and repeated stress exposed mice. Two-way repeated measures ANOVA, main effects of frequency $(\mathrm{F}=23.01, \mathrm{p}<$ 0.0001) and stress exposure $(\mathrm{F}=7.37, \mathrm{p}=0.004)$ with a significant interaction $(\mathrm{F}=3.229, \mathrm{p}=0.0031) . \mathrm{C})$ Varied number of light pulses at $10 \mathrm{~Hz}$ stimulation induce different peak concentrations of norepinephrine between stress naïve, single stress exposed, and repeated stress exposed mice. Two-way repeated measures ANOVA, main effects of frequency $(\mathrm{F}=21.27, \mathrm{p}<0.0001)$ and stress exposure $(\mathrm{F}=$ 8.09, $\mathrm{p}=0.0027)$ with a significant interaction $(\mathrm{F}=3.721, \mathrm{p}$ $=0.0033)$. Mean \pm SEM; $\mathrm{n}=7-8$ slices/group from $5-6$ mice/group. $\quad{ }^{*} \mathrm{p}<0.05,{ }^{* *} \mathrm{p}<0.05,{ }^{* * *} \mathrm{p}<0.005, \quad$ and **** $\mathrm{p}<0.0001$.
$5,10,20$ pulses at $5 \mathrm{~Hz}$ or $10 \mathrm{~Hz}$ ) protocols, and were chosen to encapsulate a range of physiologically relevant noradrenergic firing patterns $^{24-26}$. Repeated restraint stress exposure significantly increased NE release across a range of stimulation frequencies with the largest differences observed at high phasic frequencies (Fig. 3A). Stress naïve and single stress exposed animals did not significantly differ from one another. Similar results were observed with $5 \mathrm{~Hz}$ (Fig. $3^{B}$ ) and $10 \mathrm{~Hz}$ (Fig. 3C) phasic stimulations with the larger differences observed with increased pulses (approximately $3 \cdot 3^{-}$to $5^{-}$ fold difference following repeated stress exposure as compared to naïve and single stress conditions).

Finally, in order to examine the role $\alpha_{2}$-adrenergic receptors may play at the noradrenergic terminals in the vBNST, we perfused the slices with the selective $\alpha_{2}$ adrenergic antagonist idazoxan. In both naïve and single stress exposed mice, $10 \mu \mathrm{M}$ idazoxan significantly increased NE release (Fig. 4A and 4B) across a range of stimulation frequencies. Following repeated 
restraint stress, however, $\alpha_{2}$-antagonism failed to alter NE release (Fig. 4C). These data suggest that a loss in sensitivity at the $\alpha_{2}$-autoreceptor may underlie increased release of NE in mice that have experienced chronic stress. Furthermore, these data are consistent with experiments conducted in rat examining how morphine withdrawal and social isolation stress regulate $\mathrm{NE}$ release ${ }^{17-18}$, suggesting that this may be a common mechanism to elevate NE levels across species following traumatic stress.

The alterations of noradrenergic release properties we have shown may illustrate important underlying neurobiological mechanisms of psychiatric disorders. We all experience stress to some degree in our daily lives, but the transition from "normal" stress to maladaptive stress likely alters neuronal systems. Our data here, indicate that one of these systems altered by repeated stress exposure is the noradrenergic system which shows greater response to optogenetic stimuli and less control by inhibitory autoreceptors. A greater understanding
$\mathbf{A}$ Naive

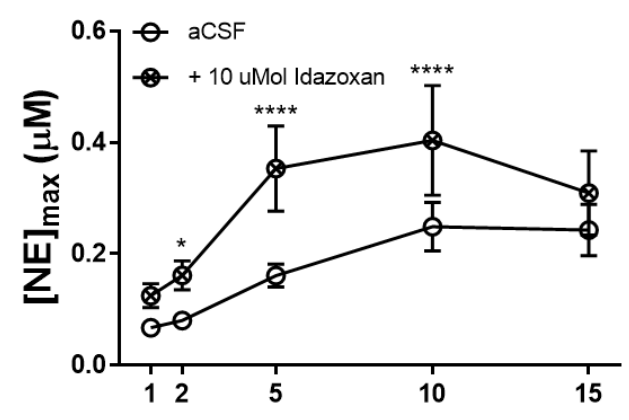

Frequency $(\mathrm{Hz})$ of 20 Light Pulses $(5 \mathrm{~ms}, 473 \mathrm{~nm})$

B

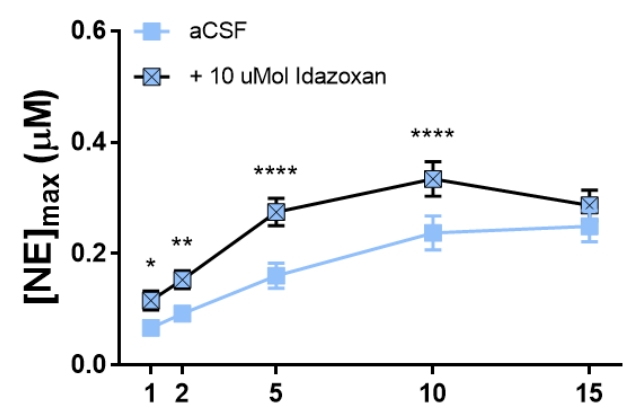

Frequency $(\mathrm{Hz})$ of 20 Light Pulses $(5 \mathrm{~ms}, 473 \mathrm{~nm})$

C

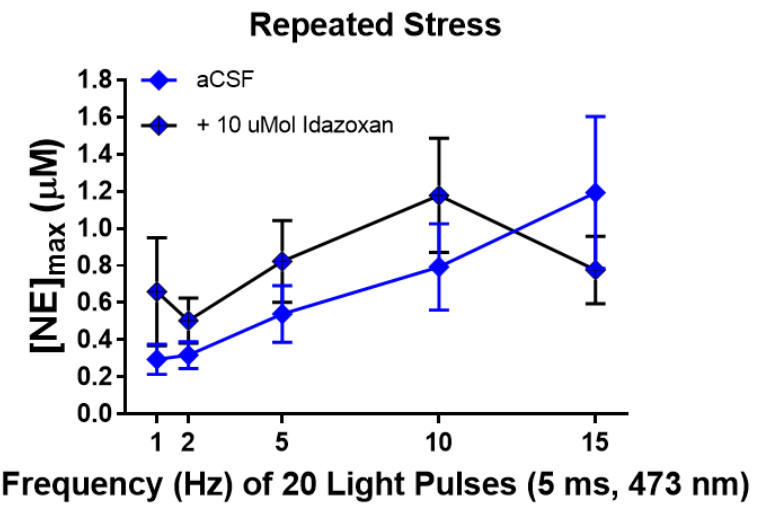

Figure 4. The a2-adrenergic autoreceptor antagonist, idazoxan $(10 \mu \mathrm{Mol})$, increases peak concentrations of norepinephrine ([NE]max) in stress naive $(\mathrm{A}), \mathrm{F}=$ 11.05, $\mathrm{p}=0.02$, and single stress (B), $\mathrm{F}=74.18, \mathrm{p}=$ 0.0001 , but not repeated stress (C) mice, $p>0.05$. $\mathrm{aCSF}=$ artificial cerebrospinal fluid. Mean \pm SEM $; \mathrm{n}=$ 6-7 slices/group from 5-6 mice/group. ${ }^{*} \mathrm{p}<0.05$, ${ }^{* *} \mathrm{p}<0.05,{ }^{* * *} \mathrm{p}<0.005$, and ${ }^{* * * *} \mathrm{p}<0.0001$.

of how this transition occurs, such as the duration or intensities of stress exposures necessary to alter NE function, the persistence of this effect, and additional mechanisms that contribute to these adaptations, are still needed to further enhance our knowledge of stress disorders. 
Furthermore, our data here show that the DBH:Cre(+/-)::Ai32(+/+) mouse will be a useful tool to continue to investigate these processes, both in terms of adaptation within the noradrenergic circuitry itself, and in the subsequent neural systems that are modulated by NE. Regardless, this elevated noradrenergic tone may relate to hyperarousal states in disorders such as PTSD4, altered affect $^{1}$, and susceptibility for addiction ${ }^{3}$.

\section{$\underline{\text { Methods }}$}

Animals and Housing. Adult male and female mice were tested with sex counterbalanced across groups. Selective expression of ChR2 in noradrenergic neurons was achieved by breeding a cross between DBH:Cre(+/-)::Ai32(+/+) mouse with a Ai32(+/+) mouse. Mice were housed with littermates in a temperature controlled vivarium with a 12:12 h light-dark cycle with lights on at $0700 \mathrm{~h}$, and had ad libitum access to food and water. All procedures were approved by the Institutional Animal Care and Use Committee of the University of North Carolina at Chapel Hill. Stress Procedures. Mice were placed in custom in-house modified ventilated $50 \mathrm{~mL}$ conical tubes for $2 \mathrm{~h}$. Mice in the single stress exposure condition were tested the day following restraint. Mice in the repeated stress exposure condition were underwent restraint procedures for $2 \mathrm{~h} / \mathrm{day}$ for 5 consecutive days. These mice were tested the day following the fifth restraint session.

Corticosterone Analysis. Mice were decapitated following restraint stress or from homecage (at 12:00 pm) and trunk blood was collected into heparinized tubes. Blood samples were immediately centrifuged (2000 x g for 10 minutes), plasma was isolated, placed on dry ice, and stored at $-80^{\circ} \mathrm{C}$ until analysis. Plasma was analyzed for corticosterone content using a commercially available colorimetric ELISA kit (Arbor Assays; Ann Arbor, MI), according to the manufacturer's instructions. All samples were run in duplicate.

\section{Double Fluorescent In Situ Hybridization (FISH).}

Brains were rapidly removed and flash frozen on dry ice for a minimum of 5 minutes, and then stored at $-80{ }^{\circ} \mathrm{C}$ for no more than 1 week prior to slicing. Sections were then sliced on a cryostat (Leica 30os, Germany) at $18 \mu \mathrm{m}$ and directly mounted onto slides, and stored at $-80{ }^{\circ} \mathrm{C}$ prior to 
the FISH procedure. FISH was performed using the RNAScope kit (ACD Biotechne) according to the manufacturer's instructions (except the time for protease IV step was reduced to $15 \mathrm{~min}$ ) using antisense probes against Dbh (Mm-Dbh-C2 400921-C2) and cFos (Mm-Fos-C3 316921-C3). Sections were imaged on a Zeiss 800 confocal microscope using identical settings.

Slice Preparation, Electrophysiology, and Electrochemistry Recordings. Mice were deeply anesthetized (isoflurane), decapitated, and brains were harvested and placed in ice-cold sucrose for slicing (ACSF in mM: 194 sucrose, $20 \mathrm{NaCl}, 4.4 \mathrm{KCl}, 2 \mathrm{CaCl}_{2}, 1 \mathrm{MgCl}_{2}, 1.2 \mathrm{NaH}_{2} \mathrm{PO}_{4}$, 10 glucose, $26 \mathrm{NaHCO}_{3}$ ) that had been oxygenated with $95 \% \mathrm{O} 2,5 \% \mathrm{CO} 2$ for at least $15 \mathrm{~min}$. Brains were sliced at $300 \mu \mathrm{m}$ using a Leica VT100o (Germany). Following slicing, brains were incubated in oxygenated ACSF (in mM: $124 \mathrm{NaCl}, 4.4 \mathrm{KCl}, 2 \mathrm{CaCl}_{2}, 1.2 \mathrm{MgSO}_{4}, 1 \mathrm{NaH}_{2} \mathrm{PO}_{4}, 10$ glucose, 26 $\mathrm{NaHCO}_{3}, 34^{\circ} \mathrm{C}$ ) and allowed to incubate for at least 30 minutes. Slices were transferred to the electrophysiology or electrochemistry rigs for patch clamp or fast scan cyclic voltammetry, respectively. Each rig perfused oxygenated ACSF $\left(28-30^{\circ} \mathrm{C}\right)$ through the bath at $2 \mathrm{ml} / \mathrm{min}$. Cells expressing ChR2-eYFP were acquired using whole-cell voltage clamp and then switched to current-clamp mode (in mM: 135 gluconic acid-potassium, $5 \mathrm{NaCl}, 2 \mathrm{MgCl}_{2}, 10 \mathrm{HEPES}$, o.6 EGTA, $4 \mathrm{Na}_{2} \mathrm{ATP}, 0.4 \mathrm{NA}_{2} \mathrm{GTP}$ ). Because NE neurons are spontaneously active, cells current was injected to keep the membrane potential at $-70 \mathrm{mV}$ and 10, $5 \mathrm{~ms}$ light pulses were applied with varying frequency $\left(1,2,5,10\right.$, and $15 \mathrm{~Hz}$.) Electrochemical recordings were made as described previously ${ }^{27}$. Carbon fiber microelectrodes were fabricated in house with fiber lengths 50-100 $\mu \mathrm{m}$. Electrodes were calibrated with 3 concentrations of NE: 0.1 $\mu \mathrm{M}, 1.0 \mu \mathrm{M}$, and $10 \mu \mathrm{M}$ NE. By graphing the peak current induced by each concentration of NE, we could draw a line of best fit whose slope was used as the current-concentration calibration factor for that electrode. Using a custom built potentiostat (University of Washington, Seattle) and TarHeel CV written in laboratory view (National Instruments), a triangular waveform (-0.4 V to $1.3 \mathrm{~V}$ ) was applied at $10 \mathrm{~Hz}$. Slices were optically stimulated with 5 -ms blue (490 $\mathrm{nm}$ ) light pulses down the submerged 40x objective. Stimulation parameters included single pulse; 2, 5, 10, 20 pulses at either $5 \mathrm{~Hz}$ or $10 \mathrm{~Hz}$; and 20 
pulses at 1, 2, 5, 10, and $15 \mathrm{~Hz}$. Each recording began with $2 \mathrm{~s}$ (20 voltammograms) of recording before stimulus delivery. Recordings were separated by $>5$ min. Voltammograms were analyzed with HDCV (UNC Chapel Hill) with NE currents isolated using principal component regression analysis, as described previously ${ }^{28}$, and $[\mathrm{NE}]_{\max }$ was determined with Clampfit 10.6 software (Molecular Devices, Sunnyvale, CA). $10 \mu \mathrm{M}$ idazoxan (Sigma-Adrich, St Louis, MO) in ACSF was bath applied for $>10$ min before testing.

Data Analysis and Statistics. Data were analyzed using GraphPad Prism 7.0 and are represented as mean \pm SEM. CORT comparisons were conducted using an unpaired Student's $t$ test. Two-way ANOVAs were performed on all NE release analyses with repeated factors of Frequency (Fig. 3A and 4A) or Number of Light Pulses (Fig. 3B and C; 4B and C) and Drug Treatment (Fig. 4). Tukey's or Sidak's post hoc tests were conducted where appropriate. Significant differences were represented at ${ }^{*} p<0.05,{ }^{* *} p<0.05,{ }^{* * *} p<0.005$, and ${ }^{* * * *} p<0.0001$.

\section{Supporting Information.}

Abbreviations. ACSF $=$ artificial cerebrospinal fluid. BNST $=$ bed nucleus of the stria terminalis. ChR2 = channelrhodopsin. CORT $=$ corticosterone. FSCV $=$ fast-scan cyclic voltammetry. $\mathrm{NE}=$ norepinephrine.

\section{Author Information.}

zoemce@email.unc.edu Tel: (919)966-8637

\section{Author Contributions.}

Concept and design, Z.A.M. and K.T.S.; K.T.S. responsible for electrode fabrication, FSCV experiments, data analysis, writing the manuscript; V.H.M and J.B. responsible for CORT analysis; K.M.B. responsible for FISH; D.P. and M.M.P. responsible for electrophysiological recordings; I.M.B participated in stress procedures, electrode fabrication, and FSCV experiments; J.L.L. and S.R.J responsible for HPLC; Z.A.M. responsible for writing the manuscript.

\section{Funding Sources.}


This research was funded by NIAAA grants: Ko1AA023555, Uo1AA020911, U24AA025475, R01AA019454, R01AA026537, F32AA026485, and T32AA007573. NINDS grant: T32NSo07431

\section{Acknowledgements.}

The authors would like to thank Dr. Patricia Jensen for generating and providing the DBH::Cre mice for these experiments. We also thank the Hooker Imaging Core at UNC and support from the Bowles Center for Alcohol Studies at UNC. We would like to thank Dr. Thomas Kash for comments on a previous version of the manuscript. 


\section{References}

1. Morilak, D. A.; Barrera, G.; Echevarria, D. J.; Garcia, A. S.; Hernandez, A.; Ma, S.; Petre, C. O., Role of brain norepinephrine in the behavioral response to stress. Prog Neuropsychopharmacol Biol Psychiatry 2005, 29 (8), 1214-24.

2. Schmidt, K. T.; Weinshenker, D., Adrenaline rush: the role of adrenergic receptors in stimulantinduced behaviors. Mol Pharmacol 2014, 85 (4), 640-50.

3. Weinshenker, D.; Schroeder, J. P., There and back again: a tale of norepinephrine and drug addiction. Neuropsychopharmacology 2007, 32 (7), 1433-51.

4. $\quad$ Southwick, S. M.; Bremner, J. D.; Rasmusson, A.; Morgan, C. A., 3rd; Arnsten, A.; Charney, D. S., Role of norepinephrine in the pathophysiology and treatment of posttraumatic stress disorder. Biol Psychiatry 1999, 46 (9), 1192-204.

5. Foote, S. L.; Bloom, F. E.; Aston-Jones, G., Nucleus locus ceruleus: new evidence of anatomical and physiological specificity. Physiol Rev 1983, 63 (3), 844-914.

6. Moore, R. Y.; Bloom, F. E., Central catecholamine neuron systems: anatomy and physiology of the norepinephrine and epinephrine systems. Annu Rev Neurosci 1979, 2, 113-68.

7. Robertson, S. D.; Plummer, N. W.; de Marchena, J.; Jensen, P., Developmental origins of central norepinephrine neuron diversity. Nat Neurosci 2013, 16 (8), 1016-23.

8. Woulfe, J. M.; Flumerfelt, B. A.; Hrycyshyn, A. W., Efferent connections of the A1 noradrenergic cell group: a DBH immunohistochemical and PHA-L anterograde tracing study. Exp Neurol 1990, 109 (3), 308-22.

9. Banihashemi, L.; Rinaman, L., Noradrenergic inputs to the bed nucleus of the stria terminalis and paraventricular nucleus of the hypothalamus underlie hypothalamic-pituitary-adrenal axis but not hypophagic or conditioned avoidance responses to systemic yohimbine. J Neurosci 2006, 26 (44), 1144253.

10. Forray, M. I.; Gysling, K., Role of noradrenergic projections to the bed nucleus of the stria terminalis in the regulation of the hypothalamic-pituitary-adrenal axis. Brain Res Brain Res Rev 2004, 47 (1-3), 145-60.

11. Park, J.; Kile, B. M.; Wightman, R. M., In vivo voltammetric monitoring of norepinephrine release in the rat ventral bed nucleus of the stria terminalis and anteroventral thalamic nucleus. Eur J Neurosci 2009, 30 (11), 2121-33.

12. Phelix, C. F.; Liposits, Z.; Paull, W. K., Catecholamine-CRF synaptic interaction in a septal bed nucleus: afferents of neurons in the bed nucleus of the stria terminalis. Brain Res Bull 1994, 33 (1), 10919.

13. Ch'ng, S.; Fu, J.; Brown, R. M.; McDougall, S. J.; Lawrence, A. J., The intersection of stress and reward: BNST modulation of aversive and appetitive states. Prog Neuropsychopharmacol Biol Psychiatry 2018.

14. Cecchi, M.; Khoshbouei, H.; Javors, M.; Morilak, D. A., Modulatory effects of norepinephrine in the lateral bed nucleus of the stria terminalis on behavioral and neuroendocrine responses to acute stress. Neuroscience 2002, 112 (1), 13-21.

15. McElligott, Z. A.; Klug, J. R.; Nobis, W. P.; Patel, S.; Grueter, B. A.; Kash, T. L.; Winder, D. G., Distinct forms of Gq-receptor-dependent plasticity of excitatory transmission in the BNST are differentially affected by stress. Proc Natl Acad Sci U S A 2010, 107 (5), 2271-6.

16. Nobis, W. P.; Kash, T. L.; Silberman, Y.; Winder, D. G., beta-Adrenergic receptors enhance excitatory transmission in the bed nucleus of the stria terminalis through a corticotrophin-releasing factor receptor-dependent and cocaine-regulated mechanism. Biol Psychiatry 2011, 69 (11), 1083-90. 
17. Fox, M. E.; Studebaker, R. I.; Swofford, N. J.; Wightman, R. M., Stress and Drug Dependence Differentially Modulate Norepinephrine Signaling in Animals with Varied HPA Axis Function. Neuropsychopharmacology 2015, 40 (7), 1752-61.

18. McElligott, Z. A.; Fox, M. E.; Walsh, P. L.; Urban, D. J.; Ferrel, M. S.; Roth, B. L.; Wightman, R. M., Noradrenergic synaptic function in the bed nucleus of the stria terminalis varies in animal models of anxiety and addiction. Neuropsychopharmacology 2013, 38 (9), 1665-73.

19. Miles, P. R.; Mundorf, M. L.; Wightman, R. M., Release and uptake of catecholamines in the bed nucleus of the stria terminalis measured in the mouse brain slice. Synapse 2002, 44 (3), 188-97.

20. Xu, F.; Gainetdinov, R. R.; Wetsel, W. C.; Jones, S. R.; Bohn, L. M.; Miller, G. W.; Wang, Y. M.; Caron, M. G., Mice lacking the norepinephrine transporter are supersensitive to psychostimulants. Nat Neurosci 2000, 3 (5), 465-71.

21. Madisen, L.; Mao, T.; Koch, H.; Zhuo, J. M.; Berenyi, A.; Fujisawa, S.; Hsu, Y. W.; Garcia, A. J., 3rd; Gu, X.; Zanella, S.; Kidney, J.; Gu, H.; Mao, Y.; Hooks, B. M.; Boyden, E. S.; Buzsaki, G.; Ramirez, J. M.; Jones, A. R.; Svoboda, K.; Han, X.; Turner, E. E.; Zeng, H., A toolbox of Cre-dependent optogenetic transgenic mice for light-induced activation and silencing. Nat Neurosci 2012, 15 (5), 793-802.

22. Herr, N. R.; Park, J.; McElligott, Z. A.; Belle, A. M.; Carelli, R. M.; Wightman, R. M., In vivo voltammetry monitoring of electrically evoked extracellular norepinephrine in subregions of the bed nucleus of the stria terminalis. J Neurophysiol 2012, 107 (6), 1731-7.

23. O'Neill, B.; Patel, J. C.; Rice, M. E., Characterization of Optically and Electrically Evoked Dopamine Release in Striatal Slices from Digenic Knock-in Mice with DAT-Driven Expression of Channelrhodopsin. ACS Chem Neurosci 2017, 8 (2), 310-319.

24. Brown, E.; Moehlis, J.; Holmes, P.; Clayton, E.; Rajkowski, J.; Aston-Jones, G., The influence of spike rate and stimulus duration on noradrenergic neurons. J Comput Neurosci 2004, 17 (1), 13-29.

25. Devilbiss, D. M.; Waterhouse, B. D., Phasic and tonic patterns of locus coeruleus output differentially modulate sensory network function in the awake rat. J Neurophysiol 2011, 105 (1), 69-87.

26. Saphier, D., Catecholaminergic projections to tuberoinfundibular neurones of the paraventricular nucleus: I. Effects of stimulation of A1, A2, A6 and C2 cell groups. Brain Res Bull 1989, 23 (6), 389-95.

27. Li, C.; Sugam, J. A.; Lowery-Gionta, E. G.; McElligott, Z. A.; McCall, N. M.; Lopez, A. J.; McKlveen, J. M.; Pleil, K. E.; Kash, T. L., Mu Opioid Receptor Modulation of Dopamine Neurons in the Periaqueductal Gray/Dorsal Raphe: A Role in Regulation of Pain. Neuropsychopharmacology 2016, 41 (8), 2122-32.

28. Bucher, E. S.; Brooks, K.; Verber, M. D.; Keithley, R. B.; Owesson-White, C.; Carroll, S.; Takmakov, P.; McKinney, C. J.; Wightman, R. M., Flexible software platform for fast-scan cyclic voltammetry data acquisition and analysis. Anal Chem 2013, 85 (21), 10344-53. 